\title{
A Review on the Causes, Effects and Mitigation of Climate Changes on the Environmental Aspects
}

\author{
Muhammad Nda ${ }^{1,2}$, Mohd Shalahuddin Adnan ${ }^{1 *}$, Kabiru Abdullahi Ahmad ${ }^{3}$, \\ Nura Usman ${ }^{4}$, Mohd Adib Mohammad Razi ${ }^{1}$, Zawawi Daud ${ }^{1}$
}

\author{
${ }^{1}$ Department of Water Resources and Environmental Engineering, Universiti Tun Hussein Onn Malaysia, Batu Pahat, \\ 86400, Malaysia. \\ ${ }^{2}$ Department of Civil Engineering, The Federal Polytechnic Bida, P.M.B 55, Nigeria. \\ ${ }^{3}$ Department of Civil Engineering, Bayero University Kano, P.M.B 3011, Nigeria. \\ ${ }^{4}$ Department of Civil Engineering, Hassan Usman Katsina Polytechnic Katsina, P.M.B 2052, Nigeria.
}

Received 22 March 2018; accepted 2 October 2018, available online 24 October 2018

\begin{abstract}
Abstract Climate change is often used interchangeably with the term global warming but, it is a much broader term which includes global warming and some other climate changes that are observed on our planet over the last few decades. In recent time climate change impacts are being felt, the average global temperature is on the rise every decade since the 1970 s. Sea ice and glaciers are disappearing, rising sea levels, species are becoming extinct, droughts that render landscape more susceptible to wildfires, changing seasons and severe weather events are becoming more common. These are problems primarily caused by the emission of greenhouse gases into the environment that results to rise in global temperature. There seems to be a consensus among scientist, researchers and all other stakeholders that climate change is already happening and primarily caused by human activities, a few disagree with this view and attribute climate change as a natural phenomenon. The objective of this paper is to (i) introduce climate change in our world today, (ii) enumerate significant causes of climate change in our environment, as well as the effects (iii), suggest ways the impact of climate change due to GHG emissions and other contributors can be mitigated.
\end{abstract}

Keywords: Climate change, Greenhouse effects, Global warming

\section{Introduction}

Nowadays, the term 'climate change' is most times used interchangeably with the term 'global warming.' Though, these two terms have different meanings. A wide range of scholars defines global warming as an average increase in the temperature of the atmosphere near the earth's surface and the troposphere. While it can occur from a variety of causes, global warming often refers to the warming due to the increase in emissions of greenhouse gases (GHG) from human activities [1]. GHG include carbon dioxide, water vapour, methane, nitrous oxide, chlorofluorocarbons and others. The GHG hypothesis predicts global warming trends because of the trapping of high outgoing wave radiation from the Earth's surface by increasing concentrations of greenhouse gases. Trapping longwave radiation in the atmosphere theoretically, alters the earth's radiative energy balance and therefore, the temperature [2]. Global warming may contribute to changes in global climate patterns.

Climate change refers to any notable difference in measures of climate (e.g., temperature, precipitation, or wind) lasting for an extended period (decades or longer). Climate change may result from natural factors such as solar cycle variation, volcanic eruptions, or slow changes in the earth's orbit around the sun. Also, natural processes within the climate system, e.g. change in ocean circulation and human activities that change radiative transfer due to changes in atmosphere's composition. Other factors include deforestation (e.g. through burning fossil fuels) and the land surface (e.g. reforestation, urbanisation, desertification, etc.). Currently, the phrase climate change is growing in preferred use to global warming because it helps convey that there are other changes in addition to rising temperatures [3]. The Intergovernmental Panel on Climate Change IPCC stated that increasing amounts of carbon dioxide $\mathrm{CO}_{2}$ and other GHG will raise global temperatures and it might have profound impacts on water resources and agriculture [4].

Research investigations in recent decades confirmed climate change has mainly affected the extreme events such as drought and floods due to changes caused by natural phenomena such as rainfall and temperature patterns change within a year. One of the most significant consequences of climate change may be the alternation of the regional hydrological cycles and subsequent changes 
in water resources and streamflow regimes [5]. During the last century, trends in temperature and precipitation are observed to differ in sign and magnitude from region to region around the globe, and even within the same region [6]. The long-term effects of rising temperature and changing pattern of rain and snow are that trees and plants around the world are forced to move toward polar regions and up mountain slopes [3].

The increasing global mean temperature has been a concern for several years for example according to NASA (National Aeronautics and Space Administration), the average earth's temperature has increased by about $1^{\circ} \mathrm{F}$ during the $20^{\text {th }}$ century as small as this increase may seem its effects on our environment has established otherwise. The impact of this insignificant variation in temperature is enormous, responsible for causing changes in the hydrological cycle, the occurrence of a more substantial number of extreme rainfall events, more extended drought periods and warmer waves and more severe storms [7].

Overall, it is expected that global warming will cause increased rainfall events worldwide. Enhanced temperatures which will, in turn, increase the amount of evaporation from water bodies and storage, which may cause drought in so many regions. As well as extreme drought in some areas, flooding and erosion will increase in others. Drought-affected areas will be more susceptible to flooding once there is rain event of high intensity. Global temperature rise, will enhance droughts occurrence and with potentially devastating consequences for agricultural yield, water supply, and human health [1].

The United Nations estimates that an area of fertile soil the size of Ukraine is lost every year because of drought, deforestation, and climate instability [3] Understanding the variability of hydrological systems at the scales of basin or watershed due to climate change is of importance to policymakers and stakeholders needing to make informed decisions to develop long-term, sustainable water resource policies. The Intergovernmental Panel on Climate Change (IPCC) has emphasised the need to understand and model the relationship between climate change and the hydrological cycle at the local scale [8].

The Fifth Assessment Report of the Intergovernmental Panel on Climate Change (IPCC) has warned international communities that the increase in anthropogenic GHG emissions is resulting in a climate change problem. The expected rise in global temperature will cause changes in precipitation patterns and an increase in quantities, frequency and intensity of other critical natural hazards [9]. However, the production of consistent future agricultural yield situations remains thought-provoking due to significant variabilities in climate change predictions [10].

According to [11], the possible impacts of climate change on agriculture are highly uncertain. A substantial number of studies conducted over the past few years for many distinct places across the globe show few if any, firm conclusions of either the size or direction of impact for distinctive countries or provinces. Where apparent agreement exists, it repeatedly seems to happen since only one or two studies have been conducted using distinct climate scenario. The deduction that does arise from impact assessments is that climate change has the potential to improve the productiveness of agriculture produce significantly at most locations. Some current high yield producing areas may turn much less productive. Some now fringe areas may take advantage, while some others may seize to be productive. Regional variations of above 20 to 30 per cent are expected in crop yield in some areas and equal size losses in other regions. Change is normally expected in most areas, and there is a need to adopt practicable mitigation measures to reduce the effect to the barest minimum [12].

\section{Causes of Climate Change}

There are numerous emerging challenges in this century, and climate change is a leading environmental menace globally today. Changes in weather conditions and long-term variations (i.e., precipitation and sea level) are associated with about two-decade of global scientific and political debate. Research and development have been putting together a whole network of essential principles of knowledge to appraise the causes of climate change and related natural disasters. Rising infrastructural development, urbanisation, and industrialisation give rise to natural resources unsystematic usage, natural disasters, pollution and an irreversible imbalance of the earth's structure. The primary human-induced driver on climate change is said to be the GHG, which include carbon dioxide, methane, and nitrous oxide. Carbon dioxide is the dominant component of the modification as it contributes almost $75 \%$ of global emission, this is so as a result of fossil fuel burning [13,14].

Fig. 1 presents the atmospheric $\mathrm{CO} 2$ variations between 1958 to 2015 [15] while Fig. 2 shows the pattern of $\mathrm{CO} 2$ emission mainly caused by fossil fuel for 50 years [16]. From the statistics, it can be observed that there was an increase in variation of the atmospheric $\mathrm{CO} 2$ and $\mathrm{CO} 2$ emissions generated by fossil fuel year after year. The entire planet is affected by the results of these actions not only the polluting area, therefore, establishment of joint legislation by global governments to demand to minimise and reduce the adverse effects of human development on the universal system balance [16].

\subsection{Nature Contribution}

The weather is always changing, of course. Records are continually being broken climate increases and decreases. Nature is in a constant state of instability; there is no certainty that the current warming is not merely part of a global cycle. Temperatures have gone up and down to a considerable degree during the past 160,000 years. In this period, there have been two ice ages. In the intermediate generation from 12 th to 14 th centuries, most of the northern hemisphere enjoyed a relatively hot epoch accompany by brief glacier period that lasted intermittently until the early 19th century. A genuine part of the warming and liquefaction witness since then can be 


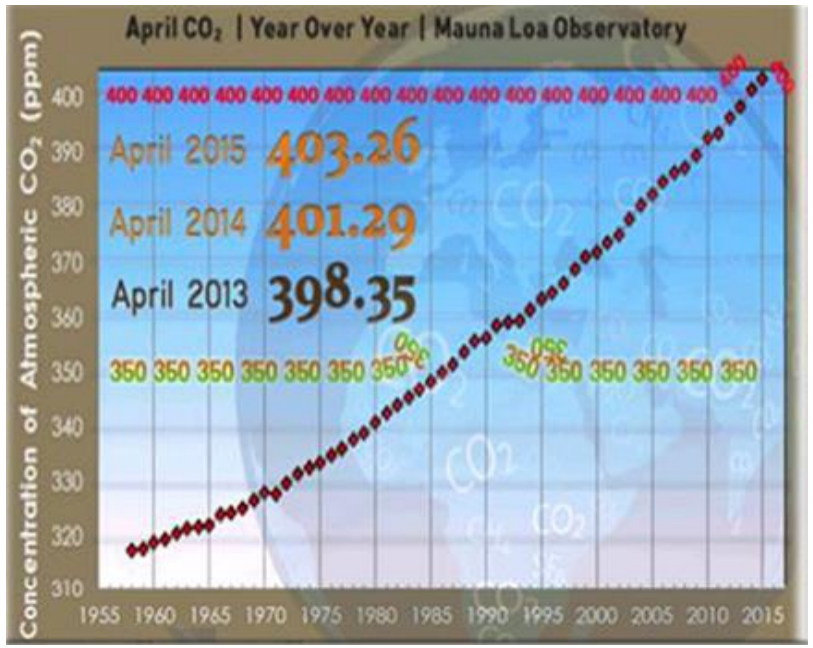

Fig. 1 - Atmospheric CO2 from 1958 - 2015 [15]

put down to a revival of that duration. Intergovernmental Panel on Climate Change (IPCC) in its latest report released, concludes that the degree and duration of warming in the 20th century cannot equitably be considered a revival. In the past ten centuries, the earth surface has witnessed warmer temperate than any period preceding it $[13,17]$. Researchers and scientist now claim to know quite a lot about causes of previous years' temperature fluctuations, regardless of the periods in view (i.e., whether millennia or few years). Planets can be cooled for months or ages by volcanic outburst filling up the upper atmosphere with a covering aerosol of elements.

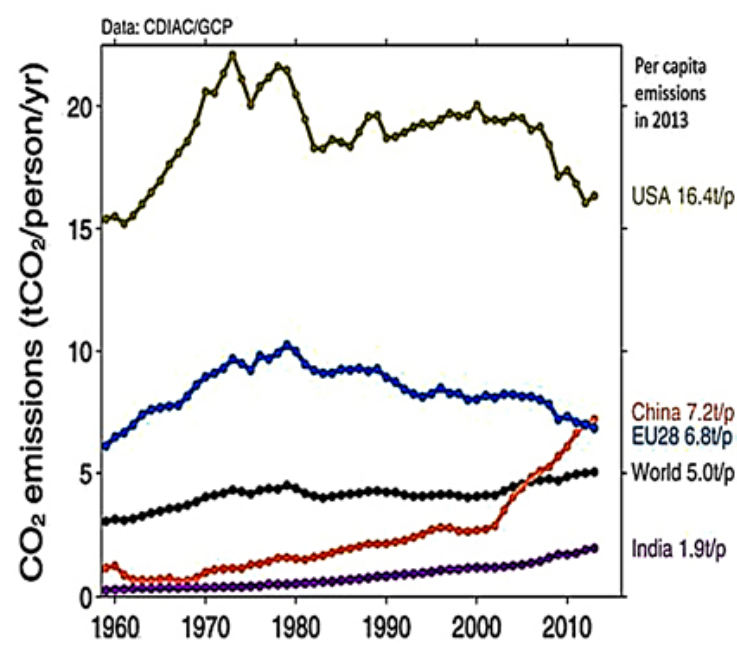

Fig. 2 - CO2 emission primarily caused by fossil fuel [16]

Volcanoes release the little amount of $\mathrm{CO}_{2}$ many million years ago this natural cause cannot explain the recent surge of temperature today. Emission of $\mathrm{CO}_{2}$ by volcanoes contribute to climate change. However, the emission generated is minor when compared to the amount of emission due to human activities. NASA confirmed that volcanic emissions of $\mathrm{CO}_{2}$ per year on the average are between 130 to 230 million tons. A single human activity of burning fossil fuel can release 100 times more into the atmosphere, about 26 billion tons of $\mathrm{CO}_{2}$ in a year. Another factor that causes changes in global weather is known as El Nino [18-20].

El Nino Southern Oscillation (ENSO) is an oscillation of the ocean and atmosphere system in the tropical area of the Pacific Ocean that affects the global weather. The water temperature of South America gets warmer because of the effects of El Nino; this warmwater phase changes global weather patterns every 3 to 10 years. South America weather is most of the time referred to as wetter than average weather, while the situation in North America is different with mild but stormier winter weather. During an El Nino warm water phase, the Atlantic Ocean will observe no or less severe storms. The rising warm air over the eastern Pacific Ocean will prevent the wind shear from forming in the Caribbean Sea. Shortly after the El Nino phase subsides, another phase with colder than ordinary water known as La Nina results [17, 20-23].

\subsection{Human Contribution}

Many scientists have concluded that the earth temperature is rising at nearly twice the rate it was some 50 years ago. This rapid warming rate and the pattern is unexplainable by natural cycles alone. The only meaningful explanation of this rising trend is to include the contributions of GHGs emitted by humans. Since the inception of Industrial Revolution in about 1750, human activities, i.e., burning of fossil fuels (including oil and coal) have dramatically risen the GHG concentration in the atmosphere [24]. These as adversely slowed the rate of heat - loss from the earth thereby creating a warming effect. The IPCC has highlighted several GHGs responsible for changing the climate, and how humans emit them in an array of ways, for example, one of the most common sources is combustion of fossil fuels in cars, factories and electricity production. Other forms include the release of methane from landfills and digestive systems of grazing animals, gases used for refrigeration and industrial processes, nitrous oxide from agro-allied products and fertilisers and desertification (removal of plants that will store $\mathrm{CO}_{2}$ ).

\subsection{Greenhouse gases}

Most scientists and researchers accept as true that the GHG effects are accountable for the global warming in recent time. Life on earth requires the essential effect of a natural greenhouse. Physicists have understood for about 200 years that certain gases in the atmosphere entrap heat radiated from the earth's surface. The gases thwart it from escaping back into space. Water vapor and carbon dioxide $\left(\mathrm{CO}_{2}\right)$ are the $\mathrm{GHG}$ in charge of sustaining the temperature of the earth.

The earth's surface would be frozen without there warming abilities. Each GHG has its peculiar radiation. Water vapour absorbs radiation with wavelengths 
between 4 and 7 micrometres; carbon dioxide absorbs wavelengths between 13 and 19 micrometres. The strengthening greenhouse effect of these gases was measured directly for hotness from the sun. The sun radiation hits the earth's surface, which in turn releases energy outwards. Some of this outgoing heat leaks into space, while some are entrapped in the atmosphere by the GHG. The radiated energy absorbed by the GHG heats the lower atmosphere. And the gases prevent the temperature of the earth's surface from going below freezing point. But, the increase in the current speed of these gases is far higher than before due to pollution such as bush burning, vehicles (especially aeroplane), power stations and industrial plants. The biggest concern of climate change stakeholders is the emission of methane and $\mathrm{CO}_{2}$ [25].

Carbon dioxide constitutes up to seventy-five per cent of the total global emission of GHG. The amount of $\mathrm{CO}_{2}$ present in the air is known to have closely shadowed global temperatures over hundreds of millions of years. Continues addition of this gas in volumes by human activities to the atmosphere is enough to trigger climate change. The exchange of $\mathrm{CO}_{2}$ between Oceans and the environment is constant, and it is absorbed and released onto the earth surface by plants and animals. Up to half of the emissions are reabsorbed by the oceans and plants, which grow faster in the air. But there is an accumulation that causes an annual rise of around $0.4 \%$ in the concentration of $\mathrm{CO}_{2}$ in the atmosphere. The atmospheric concentration of $\mathrm{CO}_{2}$ has increased from about 270 parts per million (ppm) since 1800 to today's $370 \mathrm{ppm}$ a level considered to be higher than at any time in the past 20 million years [26].

The second most significant GHG released into the atmosphere is methane which when examined molecule for the molecule is 20 times more potent has GHG than $\mathrm{CO}_{2}$. It is mostly produced through the activities of specific microorganisms that thrive in association with human beings. Guts of ruminant animals, landfills, rice paddies, methane formerly entraps beneath the ground from mines and gas pipelines), other sources are plants in stagnant lakes and other water bodies (i.e. reservoirs). This could account for up to one - fifth of global emissions from methane, resulting in $7 \%$ of total global warming [27].

\section{Effects of Climate Change}

There has been planet warming since the year 1880 from North pole to South pole, the average global temperature as increased between 1.1 and $1.60 \mathrm{~F}$ and even more in sensitive polar regions. This rise is ascending every decade, and 2013 was said to be the 7 th warmest since 1880 . The effects of climate change already appear today. The heat is melting sea ice, glaciers disappearing, shifting precipitation patterns and seasons changing. Extreme weather events are becoming more frequent; sea levels are rising, species becoming extinct. The effects of climate change adverse effects cannot be overemphasised, as the outcome of its consequences is already known to cause an estimated death of over three hundred thousand people annually and destroying the ecosystem [17].

Research and development predict that anything more than $2^{\circ} \mathrm{C}$ rise in global temperatures leads us the way to potentially disastrous outcomes. The outcomes could lead to repeated flooding, more drought and famine, increase vulnerability to disease, the possibility of war, the creation of hundreds of millions of refugees and annihilation of the entire ecosystem and species. These disastrous effects will be witnessed in our homes, our region and on the global scale. The next century will experience so many changes aside temperature, in many places, the most noticeable differences will be alterations to the hydrological cycle. There will be a noticeable shift in the availability of fresh water in the world affected by global warming. Even though there is substantial doubt in predictions of rainfall shift, it is likely to recognise some areas where it is probable that there will be a significant increment or reduction [28]. For example, in high latitudes in of the north rainfall is anticipated to lengthen during the monsoon and winter in provinces of south-east Asia, while other parts (south Europe, Central America, South Africa and Australia) expect significantly desiccative summertime. Further, the increment in temperature will signify that a higher ratio of the water falling on the Earth's superficies will dissipate. In provinces with increased rainfall, some or all the loss due to evaporation may be made up. However, there will be inherently less water available in areas with unchanged or less rainfall

The consequence of a reduced amount of precipitation and more evaporation combined, indicate less land wetness advantageous for crop production and less runoff in areas with coastal rain. This loss of land wetness can be dangerous [29]. A full hydrologic study of Asia under climate change illustrates the very distinct impacts on separate parts of the continent. In dry or semidry provinces of Asia, surface runoff is expected to drop drastically which will subdue the amount of water available for irrigation and other intention. Average yearly runoff in the basins of Brahmaputra rivers which is trans-border river which flows through China, India, and Bangladesh was estimated to lessen by $22 \%, 25 \%, 27 \%$ and $14 \%$ respectively. Substantial increases in the runoff will be encounter in other areas, for example by $37 \%$ and $26 \%$ respectively [29].

Every agriculturist comprehends the necessity to grow crops or raise animals that are compatible with the surroundings and weather conditions. The trend of rainfall and temperature during the leading element of making decisions concerning the type of plants to grow. Global warming will influence the changes. The patterns of what crops are grown and where will therefore also vary. Some worries that factors such as the degradation of many of the earth's soils mainly through erosion and the reduced rate of development in irrigation, will tend to reduce the possibilities for increased agricultural production in the future. Although, with failing proportion of population advancement, there continue 
optimism that, in the absence of significant climate change, the increment in globe food yield is likely to proceed to suit the scale in demand at least during the early decades of the twenty-first century. With the elaborate enlightenment of the essential need by the different variety and the know-how in breeding techniques and genetic manipulation usable now, there should be slight difficulty in matching crops to new weather over vast areas of the globe. At least, that is the case for crops that ripe over a year or two. Plantations reach maturity over much longer periods, as from one decade to a century or even more. The rate of climate change projection is such that, during this time, trees and shrubs may be subjected to a climate condition that is not favourable to their wellbeing. The temperature regime or the rainfall may be substantially altered, causing reduced growth or more vulnerability to disease and pests [30].

Many studies have been carried out on the effects of $\mathrm{CO}_{2}$ on fertilization and climate variability. The result of the studies indicates that the advantages of increased $\mathrm{CO}_{2}$ concentration on crop growth and yield do not always overcome the effects of excessive heat and drought. Potentials of mid-latitude cereal crop yields are projected to increase in response to little increase in temperature (between $2-3^{\circ} \mathrm{C}$ ) but decrease for larger temperature rises. The scenario is different for most tropical and subtropical regions, increase in temperature will cause a reduction in potential projected yields. The reason is that the crops are close to attaining their extreme temperature acceptance. Tropical crops yields would be even more adversely affected where there is a substantial decrease in rainfall [31].

\section{Mitigation Measures}

The member countries in the United Nations convention on climate change recognized the reality of global warming, present climate change prediction uncertainties and resolved that measures to mitigate the effects of climate change require being pointed out and taken seriously. The following are considered effective means to reduce the progress of climate change $[17,21$, 26, 32, 33].

\subsection{Eco-friendly Energy Sources}

There are two mainstream eco-friendly energy options available today which is solar and wind power. Both are as likely to benefit the developed world as well as the developing. The wind turbine blades turn on every country regardless of its geolocation on the earth. Solar panels glint on roofs in rural Kenya even more than sundrenched Australia. Renewable sources of energy to generate electricity such as wind turbines have slight or no effect on its immediate environment. Water or coal is not needed to operate these turbines; the applicability of wind turbines has cut water consumption in the energy generation sector in the United States of America by 36.5 billion gallons in 2013. Solar energy has become more accessible and used than wind turbines; electricity is generated by panels using light-sensitive semiconductors mounted on rooftops or assembled on vast arrays to supply electricity to power individual buildings or supply into grid system.

\subsection{Green Transport}

The transportation sector is one of the fastest growing contributors to carbon dioxide emissions from all sort of vehicles with $2.5 \%$ annual global rise and $7.5 \%$ in Asia where car ownership is snowballing. To reduce the amount of $\mathrm{CO}_{2}$ emissions by vehicles, there must be a change from the conventional cities design to robust urban mass transit schemes (metros, trams and underground trains). Other means of reducing $\mathrm{CO}_{2}$ emissions caused by transportation is by walking or cycling to short distances rather than using vehicles, carpooling and use of a most fuel-efficient vehicle.

\subsection{Green Building}

The existing buildings where we live, and work emit some form of $\mathrm{CO}_{2}$ because of the dependence on fossil fuels to power the daily need appliances. The use of energy efficient light bulbs, cooling and heating appliances assists in bringing down the level of $\mathrm{CO}_{2}$ released from such building's structures. For instance, in New York, the Empire State building in undergo some renovations to enhance the energy efficiency. As a result, the improvements cut down the energy usage by thirtyeight percent, saving 4.4 million dollars annually from heating and electricity bills. Some other forms of mitigation measures to be adopted include; (i)Trimming wastes generated from homes, these wastes (garbage) are disposed and buried in landfills which produces methane, a strong GHG. (ii) Eating organic and homegrown foods, reduce meat consumption and avoiding processed items since a large percentage of GHG emissions come from meat and dairy production. (iii) Introduction of polluters tax, carbon taxes make pollution activities more expensive and green solutions more affordable allowing energy efficient businesses and household to save money.

\section{Conclusion}

Given the current atmospheric concentrations of greenhouse gases, climate change is one of the most pressing challenges the world faces today. The world is already exposed to significant warming, this is a serious problem, knowing the various expected climate effects on natural systems, as well as on human and its environment. The severity of these impacts will depend in part on the seriousness of global efforts to mitigate climate change by altering the world over-dependence on fossil fuels for energy, transportation, and manufacturing to switching to renewable energies.

\section{Acknowledgement}

This Research work is supported by Postgraduate Research Grant GPPS(U699), Universiti Tun Hussein Onn Malaysia. The financial assistance is highly appreciated. 


\section{References}

[1] Dube, T., Moyo, P., Ncube, M., \& Nyathi, D. (2016). The impact of climate change on agroecological based livelihoods in Africa: A review. $J$. Sustain. Dev., 9(1), 256-263.

[2] Ramírez, J. A., \& Finnerty, B. (1996). CO 2 and temperature effects on evapotranspiration and irrigated agriculture. Journal of irrigation and drainage engineering, 122(3), 155-163.

[3] Zhang, T. C., \& Surampalli, R. Y. (2011). Impact of Greenhouse Gas Emissions and Climate Change. no. Ec, 92-108.

[4] Elgaali, E., \& Garcia, L. a. (2007). Using neural networks to model the impacts of climate change on water supplies. J. Water Resour. Plan. Manag., 133(3), 230-243.

[5] Chen, Y. N., Li, W. H., Xu, C., \& Hao, X. M. (2007). Effects of climate change on water resources in Tarim River Basin, Northwest China. J. Environ. Sci., 19(4), 488-493.

[6] Metz, B., \& Davidson, O. (2007). Climate Change 2007; Mitigation of Climate Change. Fourth Ass. New York: Cambridge University Press.

[7] Berggren, K., Olofsson, M., Viklander, M., Svensson, G., \& Gustafsson, A.M. (2012). Hydraulic impacts on urban drainage systems due to changes in rainfall caused by climatic change. $J$. Hydrol. Eng., 17(4), 92-98.

[8] Ramadan, H. H., Beighley, R. E., \& Ramamurthy, A.S. (2012). Temperature and precipitation trends in Lebanon's largest river: The Litani basin. J. Water Resour. Plan. Manag., 139(2), 175-181.

[9] Edenhofer, R., Pichs-Madruga, O., \& Sokona, Y. (2014). Climate change 2014: Mitigation of climate change: Working group III contribution to the fifth assessment report of the intergovernmental panel.

[10] Wolfe, D. W. (2011). Potential impact of climate change on agriculture and food supply. 1-7.

[11] Hall, C., Dawson, T. P., Macdiarmid, J. I., Matthews, R. B., \& Smith, P. (2017). The impact of population growth and climate change on food security in Africa: looking ahead to 2050. Int. J. Agric. Sustain.,15(2), 124-135.

[12] Ayanlade, A., Radeny, M., \& Akin-Onigbinde, A. I. (2018). Climate variability/change and attitude to adaptation technologies: a pilot study among selected rural farmers' communities in Nigeria. Geo Journal, 83(2), 319-331.

[13] Houghton, J. (2004). Global Warming; The complete briefing. (3rd ed.). New York: Cambridge University Press.
[14] Weber, E., \& Stern, P. (2011). Public understanding of climate change in the United States. American Psychologist, 66(4), 315.

[15] Kumar, P., \& Kim, K. H. (2016). Recent progress and innovation in carbon capture and storage using bioinspired materials. Applied Energy, 172, 383397.

[16] Burghila, D., Bordun, C.E., Doru, M., Sarbu, N., Badea, A., \& Cimpeanu, S. M. (2012). Climate change effects-where to next?. Agriculture and Agricultural Science Procedia, 6, 405-412.

[17] Gribbin, J. (2002). Global warming ' A Beginners Guide to our Changing Climate. (1st Ed.). New York: MacMillan.

[18] Karl, T. R., and Kevin E. T., (2003). Modern global climate change. Science, 302(5651), 1719-1723.

[19] Sato, M., Hansen, J., Koch, D., Lacis, A., Ruedy, R., Dubovik, O., Holben, B., Chin, M., \& Novakov, T. (2003). Global atmospheric black carbon inferred from aeronaut. Proc. Natl. Acad. Sci. U. S. A.,100(11), 6319-24.

[20] Hoerling, M. P., Hurrell, J. W., \& Xu, T. (2001). Tropical origins for recent North Atlantic climate change. Science, 292(5514) 90-92.

[21] Zawani M. Zahudi, MS Adnan, NF Amat, Y Erfen, NC Ali (2015). Climate Change Impacts on Rainfall Distribution at Teluk Intan Catchment, Applied Mechanics and Materials 773, 1296-1300

[22] M Nda, MS Adnan, MA Suhadak, MS Zakaria, RT Lopa (2018). Effects of Hydrological Parameters on Palm Oil Fresh Fruit Bunch Yield, IOP Conference Series: Earth and Environmental Science 140 (1), 012051

[23] Clarke, H., Lucas, C., \& Smith, P. (2013). Changes in Australian fire weather between 1973 and 2010. Int. J. Climatology., 33(4), 931-944.

[24] Zahran, S., Brody, S. D., Grover, H., \& Vedlitz, A. (2006). Climate Change Vulnerability and Policy Support. Soc. Nat. Resour., 19(9), 771-789.

[25] Good, P., Caesar, J., Bernie, D., Lowe, J. A., Van der Linden, P., Gosling, S. N., et al. (2011). A review of recent developments in climate change science. Part I: Understanding of future change in the large-scale climate system. Prog. Phys. Geogr., 35(3), 281-296.

[26] Daniel, B. Y., Freire, M., Marcus J., \& Lee, P. B. (2015). Cities and Climate Change. New York: Urban Development Series.

[27] Berbesi, L., Primio, R., Anka, Z., \& Horsfield, B. (2014). Methane leakage from evolving petroleum systems: Masses, rates and inferences for climate feedback. Earth and Planetary Science Letters, 387, 219-228. 
[28] Wu, W., Clark, J. S., \& Vose, J. M. (2014). Response of hydrology to climate change in the southern Appalachian Mountains using Bayesian inference. Hydrol. Process., 28(4),1616-1626.

[29] Lockwood, J. G. (2001). Abrupt and sudden climatic transitions and fluctuations: a review. International Journal of Climatology: A Journal of the Royal Meteorological Society, 21(9), 1153-1179.

[30] Germer, J., and Sauerborn, J. (2008). Estimation of the impact of oil palm plantation establishment on greenhouse gas balance. Environment, Development and Sustainability., 10(6), 697-716.
[31] Gopal, B. (2013). Future of wetlands in tropical and subtropical Asia, especially in the face of climate change. Aquatic Sciences., 75(1), 39-61.

[32] Branković, Č., Bray, J., Callaway, J., Dulčić, J., Gajić-Čapka, M., Glamuzina, B., Heim, I., Japec, L., Kalinski, V., Landau, S. and Legro, S., (2008). A Climate for Change: Climate change and its impacts on society and economy in Croatia", Human Development Report-Croatia.

[33] Kaddo, Jameel R. (2016). Climate Change: Causes, Effects, and Solutions. A with Honors Projects. 164, available at; $\underline{\text { HTTPs://spark.parkland.edu/ah/164 }}$ 